\title{
Formação de educadores de EJA: caminhos inovadores da prática docente
}

\author{
EJA training of educators: innovative ways of teaching practice \\ Capacitación EJA de educadores: formas innovadoras de enseñanza práctica
}

\author{
ANTONIO AMORIM* \\ MARIA LUIZA FERREIRA DUQUES ${ }^{* *}$
}

\begin{abstract}
RESUMO
Este estudo investigou as necessidades formativas de educadores baianos que atuam na EJA, a fim de desenvolver ações que contribuam para a melhoria dos processos formativos. Pela importância da temática foi preciso dialogar com Freire (1996), Di Pierro (2006), Machado (2000), Moura (2006), Pimenta (1999) e Nóvoa (1992), entre outros. A investigação se pautou na abordagem qualitativa para aprimorar os achados. Pelos resultados encontrados, os educadores revelaram a necessidade relacionada à prática docente, à gestão da escola, de Educação de Jovens e Adultos, ao currículo e à formação continuada, sendo que as necessidades correlatas à formação continuada foram enfatizadas como o maior empecilho para o trabalho na EJA. Faz-se urgente a instituição de políticas públicas voltadas a essa modalidade, pois, apesar das dificuldades, os educadores desejam um processo formativo que garanta o desenvolvimento qualificado das práticas. Conclui-se pela necessidade de se respeitar os educadores que atuam na EJA com a formulação de políticas públicas que valorizem a profissionalização desses educadores.
\end{abstract}

Palavras-chave: Formação de educadores. Práticas docentes. Educação de Jovens e Adultos.

\begin{abstract}
This study investigated the formation needs of bahian educators working in the EJA, in order to develop actions that contribute to the improvement of formation processes. By the importance of the theme it was approached the dialogue with Freire (1996), Di Pierro (2006), Machado (2000), Moura (2006), Pimenta (1999) and Nóvoa (1992), among others. The research used a qualitative approach to enhance the findings. According to the results, educators have revealed the needs regarding teaching, Youth and Adult Education school management, curriculum and continuing formation, being the needs related to continuing formation emphasized as the biggest obstacle to work on EJA. The establishment of public policies for the EJA is urgent, because, despite the difficulties, the educators seek a formation process that ensures the qualified development of practices. The results confirmed the need to respect the teachers who work in EJA with the formulation of public policies that enhance the professionalization of these educators.
\end{abstract}

Keywords: Formation of educators. Teaching practices. Youth and Adult Education.

\section{RESUMEN}

Este estudio investigó las necesidades de formación de educadores bahianos, con el fin de desarrollar acciones que contribuyan para la mejora de procesos de formación. Por la importancia del tema fue necesario dialogar con Freire (1996), Di Pierro (2006), Machado (2000), Moura (2006), Pimenta (1999) y Nóvoa (1992), entre otros. La investigación tuvo enfoque en el abordaje cualitativo para mejorar los resultados. Por los resultados encontrados, los educadores han revelado la necesidad relacionada a la práctica docente, a la gestión de la escuela de Educación de Jóvenes y Adultos, al currículo y a la formación continua, siendo que las necesidades relacionadas a la formación continua fueron enfatizadas como el mayor obstáculo para el trabajar en Educación de jóvenes y adultos. Hace urgente el establecimiento de políticas públicas para la EJA, pues, además de las dificultades, los educadores quieren un proceso formativo que garantice el desarrollo de calificado de las prácticas. La conclusión es por la necesidad de respetarse los educadores que trabajan en la EJA con la formulación de políticas públicas que valoricen la profesionalización de esos educadores.

Palabras clave: Formación de educadores. Prácticas de enseñanza. Educación de Jóvenes y Adultos.

\footnotetext{
* Professor titular pleno do Departamento de Educação do Campus I da Universidade do Estado da Bahia. Pós-doutorado em Difusão do Conhecimento pela Universidade Federal da Bahia-UFBA. Doutor em Psicologia pela Universidade de Barcelona - Espanha. E-mail: < antonioamorim52@gmail.com>.

**Professora da educação básica. Doutoranda em Memória: Linguagem e Sociedade pela Universidade Estadual do Sudoeste da Bahia-UESB. Mestre em Educação de Jovens e Adultos pela Universidade do Estado da Bahia-UNEB. Departamento de Educação. E-mail: <luizaduques@hotmail.com>.
} 


\section{INTRODUÇÃO}

A discussão acerca da formação docente no Brasil não se estabelece sem levar em consideração o fato de que somente a partir do século XX é que, efetivamente, inicia-se a expansão da escolarização básica no país. Além disso, em termos de rede pública de ensino, seu crescimento vai ocorrer no final dos anos 1970 e início dos anos 1980 .

No Brasil, a escolarização, por muitos séculos, foi propriedade exclusiva das elites, mas, com os levantes populares e com as necessidades de crescimento industrial, os investimentos públicos no ensino começaram a se fazer presentes no cenário nacional, o que implicou a demanda por mais professores. $\mathrm{O}$ atendimento desses profissionais nas escolas ocorreu, no período, através de adequações mediante cursos aligeirados de formação de professores, complementações formativas, autorizações para que não licenciados exercessem o magistério, com a admissão de professores leigos pelos sistemas de ensino.

Desse modo, a formação de professores no país, ainda, sofria impactos decorrentes das improvisações que foram feitas para o funcionamento das escolas e da rápida expansão da rede pública e privada de ensino. No caso específico da Educação de Jovens e Adultos (EJA), essa situação agravava-se ainda mais, dado o descaso secular pelo qual passava a modalidade de ensino. Os desafios à formação de professores de EJA são muitos, e é mediante a busca da compreensão dessa questão que se percebe a complexidade da mesma. Por um lado, verificase o aumento da oferta de EJA e as tentativas de inclusão social, com esforços para cobrir segmentos sociais, até há pouco tempo, negligenciados. Isso provoca a demanda por um maior número de professores para atender à modalidade. Por outro, as novas urgências impostas pelas modificações da sociedade contemporânea perpassam os diversos ramos da vida humana e adentram a escola, pressionando práticas educativas que contribuam para a formação de um aluno democrático, contemporâneo e com condições exequíveis para alavancar essa nova sociedade.

Considerando a incipiência dos processos formativos dos educadores que atuam na EJA, no país, de modo geral, e em estados e municípios, de forma mais específica, é que este estudo se concentra no enfoque do desenvolvimento e aperfeiçoamento da prática docente de educadores baianos.

O processo de escolarização dos jovens e adultos está relacionado aos sistemas formativos dos educadores, que, no enfoque específico da EJA, estão cada vez mais escassos no cenário educacional. Isso despertou as inquietações que desembocaram nessa proposta. Por isso, procurou-se responder à seguinte problemática: quais são as necessidades formativas dos educadores de EJA e seus significados para a formação dos jovens e adultos?

Partindo dessa inquietação, que constitui uma problemática enfrentada pela maioria dos professores da modalidade, e por entender a importância de se pensar em alternativas que venham equacionar ou amenizar as dificuldades enfrentadas pelos mesmos no que se refere à formação e consequente melhoria da prática docente, este estudo apresenta uma possibilidade de contribuição para o contexto da EJA. Nesse sentido, tem como objetivo investigar as necessidades formativas de educadores da EJA, a fim de desenvolver ações que contribuam para a melhoria da qualidade dos processos formativos de educadores e educandos.

O estudo se organiza em momentos imbricados. Após esta introdução, em que se esclarece o objeto de estudo e suas inquietações, avança-se em direção aos procedimentos metodológicos e à caracterização dos sujeitos envolvidos na investigação. Em seguida, trabalham-se as estruturas formativas dos educadores, seguindo com a discussão da formação continuada em EJA e com as novas perspectivas formativas para a modalidade. Na sequência, são apresentados os resultados do estudo com ênfase na formação continuada e, por fim, as considerações e recomendações para a melhoria da formação em EJA.

\section{Procedimentos MeTodológicos DA INVESTIGAÇÃO E CARACTERIZAÇÃO DOS SUJEITOS}

Na busca pelo alcance dos objetivos, esta investigação se fundamenta na abordagem qualitativa que "implica compreender o conhecimento como produção e não como apropriação linear de uma realidade que se nos apresenta" (GONZÁLEZ, 2002, p. 05). Parte-se, assim, do fundamento de que há uma íntima interdependência entre o sujeito e o objeto (BOGDAN; BIKLEN, 1994).

Entende-se a construção e interpretação das informações na pesquisa qualitativa como sendo um processo que mantém um caráter recorrente com os instrumentos usados na mesma. Dessa forma, a investigação é caracterizada como sendo um estudo de caso, por emanar do desejo de compreender fenômenos sociais complexos e apresentar as características significativas e holísticas de eventos da vida real (YIN, 2001). Os estudos de caso mais comuns são os que enfocam somente uma unidade: um sujeito, um pequeno grupo, um programa, um evento, uma instituição. Mas é possível que ocorram estudos de casos múltiplos (YIN, 2001), por meio dos quais vários estudos são conduzidos simultaneamente. São estudos que, de acordo com Alves-Mazzotti e Gewandsznajder (2002), podem ser realizados com vários indivíduos (como, por 
exemplo, professores alfabetizadores bem-sucedidos) ou com várias instituições (diferentes escolas que estão desenvolvendo determinado trabalho). Este estudo envolve 14 educadores de oito instituições baianas que ofertam a EJA, em diferentes cidades baianas, levando em consideração a região geográfica. Optou-se pelo estudo de caso múltiplo como estratégia capaz de ajudar a entender os processos formativos desses educadores.

Um aspecto essencial para o levantamento das informações do problema em estudo foi a definição do ambiente de realização desta pesquisa e dos indivíduos envolvidos. Segundo Marconi e Lakatos (2009), a escolha dos elementos da amostra deve ser feita de tal forma que seja a mais representativa possível do todo. Para que isso aconteça, esta deve ser selecionada convenientemente, tornando-se um subconjunto do universo. Considerando essas definições, o universo desta pesquisa e os sujeitos envolvidos na busca da solução da problemática são os educadores e profissionais da educação (gestores e coordenadores pedagógicos) de escolas baianas que ofertam a modalidade de EJA.

A delimitação dos sujeitos entrevistados e/ou observados na dinâmica da pesquisa, assim como o seu grau de representatividade na situação investigada, considerou o conhecimento da realidade educacional do solo em que o estudo se assenta. O passo inicial foi a realização de um diagnóstico situacional em que, por meio de um mapeamento da modalidade e dos profissionais atuantes, foi possível ter uma dimensão do quantitativo de educadores e suas áreas de atuação. Dessas constatações, e pensando no objetivo a ser atingido, optou-se por selecionar educadores que fornecessem condições de análises mais profundas, que não focalizassem apenas o momento atual. Profissionais que trouxessem os condicionantes de formação que acompanham os educadores, considerando, pois, a formação, a trajetória profissional, a participação na Educação de Jovens e Adultos, os diferentes tempos de atuação na docência em EJA, bem como as áreas de atuação no trabalho educativo na modalidade. Nesse quesito é importante considerar que foram investigados educadores que atuavam entre uma $\mathrm{e}$ duas instituições de EJA, e alguns deles desenvolviam trabalhos em áreas diferentes da correspondente à sua formação. Destarte, a amostra considerou educadores que figuraram um recorte temporal, variando entre um e 22 anos de atuação na educação de jovens e adultos e que, portanto, apresentaram trajetórias formativas e práticas pedagógicas bastante distintas.

Como instrumento de coleta e produção de dados, utilizou-se a entrevista semiestruturada, aplicada aos educadores das escolas investigadas que ofertam a EJA. Realizou-se também o processo de observação, com registro diário dos dados pertinentes à pesquisa. Os materiais coletados foram tratados com base na análise de conteúdo proposta por Bardin (1988), garantindo-se a formação de categorias significativas para uma melhor compreensão da realidade estudada.

Uma metodologia apropriada, com procedimentos justificados e análise densa, criteriosa e que indique avanços para a área de conhecimento, é um importante critério de rigor e legitimidade científica (BARDIN, 1988), e esses aspectos foram os caminhos trilhados em direção aos achados desta pesquisa.

\section{ESTRUTURA FORMATIVA DE EDUCADORES}

A história da formação de professores em cursos específicos no Brasil tem como marco os fins do século XIX, que assinalam a ascensão das Escolas Normais como instituições voltadas à formação de professores para as primeiras letras. Nesse período, poucos eram os contemplados com a oferta de escolarização, e essa oferta ficava restrita aos níveis primários. Com a chegada do século XX, emerge a necessidade de se pensar na formação de professores para o secundário. Surge também a preocupação de instituir cursos específicos. Nesse sentido, a garantia da formação de professores para o secundário traz consigo a imperativa necessidade da instituição de centros especializados de formação, decorrendo, daí, a criação das universidades.

Nos anos 1930, a partir da formação de bacharéis, propõe-se o acréscimo de um ano com disciplinas da área de educação para a obtenção da licenciatura dirigida à formação de docentes para o ensino secundário (GATTI; BARRETO, 2009). Esse formato contemplou também o curso de Pedagogia, destinado a formar bacharéis especialistas em educação.

No percurso que atravessa a formação de professores, a partir da década de 1960, muitas foram as legislações que surgiram no sentido de regulamentar os currículos dos cursos destinados à formação docente. Aparece no período após 1960 a Lei 4.024/61, seguida da 5.540/68. Logo depois, instituiu-se a 5.692/71 e ainda a 7.044/82.

No que versa sobre o campo da EJA, em fins da década de 1980, instituições de ensino superior debateram a atuação do pedagogo e sua habilitação. Desses debates estabelecidos entre as faculdades de Educação, emergiu, segundo Machado (2008), a compreensão de que os pedagogos deveriam ser habilitados prioritariamente como professores, podendo atuar na gestão pública da educação em variados campos, como diretores, coordenadores, supervisores, mas sua matriz de formação era de fato o magistério dos anos iniciais do 10 grau. A partir daí, alguns cursos de Pedagogia passaram a ter ênfases específicas em suas habilitações. Essas experiências resultaram nos cursos de Pedagogia com ênfase em EJA. 
Em relação às licenciaturas em geral, naquela época, o Conselho Federal de Educação normatizou, por meio de suas resoluções, um currículo mínimo a ser cumprido em cada uma das licenciaturas. Definiu, também, as disciplinas obrigatórias e privilegiou, essencialmente, a formação em área específica, com uma complementação pedagógica ao final do curso.

Quanto às licenciaturas nos vários campos de conhecimento, necessárias para a atuação nas áreas específicas, o licenciando ficava entre duas formações estanques, “[...] com identidade problemática: especialista em área específica ou professor? Matemático ou professor de Matemática? Geógrafo ou professor de Geografia? Físico ou professor de Física?" (GATTI; BARRETO, 2009, p. 42).

Os documentos legais e as discussões desencadeadas a respeito dos modelos formativos propostos antes da LDBEN 9394/96 dão conta de atestar muitas deficiências formativas presentes nos modelos adotados. Deficiências essas que deixaram seus ranços na educação contemporânea, ainda que, em muitos aspectos, amenizados com a promulgação da Lei de Diretrizes e Bases da Educação Nacional - LDBEN 9394/96.

Embora a estrutura dos cursos formativos tenha carregado as marcas de legislações anteriores por um período razoável, foi a partir da LDB de 1996 que os cursos de formação de professores começaram a sofrer modificações. Através dos seus artigos 62 e 63, a LDBEN de 1996 estipulou, para os professores da educação básica, a exigência de nível superior. Para o cumprimento dessa normatização, foi dado o prazo de dez anos para os sistemas de ensino fazerem as adequações à legislação vigente. Esses dois artigos deram vasão à possibilidade de as universidades organizarem a formação de professores de acordo seus próprios programas institucionais, com a ressalva de que os cursos ofertados fossem em licenciatura plena, com possibilidade de incorporar os Institutos Superiores de Educação (ISEs) e a Escola Normal Superior (ENS).

No ano de 2002, instituíram-se as Diretrizes Curriculares Nacionais para a Formação de Professores para a Educação Básica, cujo foco textual repousa no desenvolvimento de competências individuais, sociais e profissionais dos educadores. De acordo com essas diretrizes, a formação de professores, com atuação nos diferentes níveis e modalidades da educação básica, deveria observar princípios norteadores do preparo para o exercício profissional específico, levando em conta a formação de competências necessárias à atuação profissional e também a pesquisa, centrada no ensino e na aprendizagem, para compreensão do processo de construção do conhecimento.

Ainda que tenha havido ajustes em razão das diretrizes, constata-se, nas licenciaturas dos professores especialistas, a prevalência da histórica ideia de oferecimento de formação na área disciplinar, específica, com grande peso em número de disciplinas, basicamente sem integração com as disciplinas pedagógicas (GATTI; BARRETO, 2009).

O debate acerca das estruturas formativas de professores continua a movimentar as discussões e a compor as seções das legislações educacionais. Em 2006, após muito debate, o Conselho Nacional de Educação aprovou a Resolução no 1, de 15/05/06 (BRASIL. MEC/ CNE, 2006), com as diretrizes curriculares nacionais para os cursos de Pedagogia, em nível de licenciatura. Nesse sentido, conferiu a esses cursos a formação de professores para atuar na educação infantil e anos iniciais do ensino fundamental, assim como no ensino médio, na modalidade normal, e na educação de jovens e adultos.

A Resolução CNE/CP no 1/06 conferiu diversas atribuições aos cursos de Pedagogia. Para além da formação de professores para exercer funções de magistério, $\mathrm{o}$ art. $4^{\circ}$ estabelece que as atividades docentes, também, compreendem participação na organização e gestão de sistemas e instituições de ensino.

Dessa forma, organizar uma matriz curricular que levasse em consideração todas essas postulações tornava-se tarefa difícil de ser executada, sobretudo se fosse considerada a dinâmica dos cursos noturnos de licenciatura, formados essencialmente por alunos trabalhadores. As dificuldades encontradas para efeito de operacionalização dessas normatizações legais têm conduzido a algumas simplificações que podem afetar o perfil dos formados.

\section{FORMAÇÃO CONTINUADA NO CONTEXTO DA EJA}

A formação continuada, ofertada nas últimas décadas, tem se pautado no aprofundamento de conhecimentos como sendo a condição para a realização do trabalho educativo diante das novas tecnologias, da rápida difusão de conhecimentos, das modificações nos processos educativos e suas repercussões na vida em sociedade. Contudo, os conhecimentos construídos pelos professores durante esses processos formativos não têm alcançado os educandos de EJA de uma forma totalmente satisfatória, já que o desempenho de conhecimentos escolares por parte da maioria dos alunos ainda se apresenta deficitário.

No caso de boa parte dos municípios baianos, os estudantes vêm revelando que não se percebem contemplados, em suas demandas, através do que a escola propõe. Isso denota carência na formação docente, uma vez que o professor, muitas vezes, atua na EJA do mesmo modo que atua no ensino regular e não busca metodologias 
adequadas aos educandos da EJA. Destarte, os desafios da EJA estão intimamente vinculados aos do processo de formação docente.

Hoje, ainda é bastante comum a existência de práticas docentes desconexas do ideal de atuação direcionado à EJA. Isso porque, na maioria das vezes, o educador de EJA é também pertencente ao ensino regular, e grande parte dos conhecimentos que possui, e mesmo suas concepções metodológicas, são organizados a fim de atender a um ensino de crianças e adolescentes. Como menciona Di Pierro (2003, p. 17),

Os docentes que atuam com os jovens e adultos são, em geral, os mesmos do ensino regular. Ou eles tentam adaptar a metodologia a este público específico, ou reproduzem com os jovens e adultos a mesma dinâmica de ensino-aprendizagem que estabelecem com crianças e adolescentes.

Professores da EJA requerem um conhecimento diferenciado, pois estão em contato com um tipo diferente de aluno no que diz respeito ao perfil, necessidades, interesses e situações de vida. Nessa mesma direção, Machado (2000) revela que é quase unânime a constatação das dificuldades enfrentadas pelos professores em suas práticas e das necessidades de preparação específica dos professores que atuam em EJA.

A necessidade de posturas distintas para se relacionarem em classe coloca os educadores de EJA diante de desafios que requerem formação continuada. $\mathrm{Na}$ maioria dos municípios baianos, os espaços de formação e discussão da condição da EJA limitam a poucos contatos aligeirados e temáticos em serviço, promovidos e estimulados, muitas vezes, pelas próprias instituições que ofertam a modalidade.

Diante do cenário nacional que apresenta desafios e perspectivas no campo da formação docente, as análises acerca da formação do professor requerem um aporte legal que garanta a sustentação das discussões nesse campo. Desse modo, o Plano Nacional de Educação, Lei no 13.005/2014, estabelece, em suas metas 15 e 16, a garantia da formação inicial e continuada para os profissionais da educação em suas respectivas áreas de atuação. A Lei de Diretrizes e Bases da Educação Nacional, no 9.394/96, estipula:

Art. 67. Os sistemas de ensino promoverão a valorização dos profissionais da educação, assegurando-lhes, inclusive nos termos dos estatutos e dos planos de carreira do magistério público:

[...] II - aperfeiçoamento profissional continuado, inclusive com licenciamento periódico remunerado para esse fim;

[...] V - período reservado a estudos, planejamento e avaliação, incluído na carga de trabalho.
Como estabelece a legislação, a formação continuada é um direito do educador, mas, embora haja documentos legais que assegurem e privilegiem a instituição de políticas públicas no âmbito da formação docente, a fronteira entre o texto legal e a concreta operacionalização dessas leis ainda é grande. Como revela Soares (2006), apesar de certo consenso presente nas discussões teóricas e na legislação acerca da necessidade de qualificação específica para o professor de jovens e adultos, ainda hoje é recorrente a ausência de políticas específicas para a formação dos professores de Educação de Jovens e Adultos.

Essa configuração nacional envolve diversos educadores de vários municípios que ofertam a EJA. Com base nas observações em contexto e mediante informações colhidas na gestão da educação, a formação continuada dos docentes da EJA do estado se dá por meio de ações pontuais, ainda distantes de alcançarem o ideal formativo dos docentes que atuam nessa modalidade.

No intuito de orientar o trabalho pedagógico das escolas, os municípios baianos costumam oferecer jornadas pedagógicas, no início do ano letivo, com oficinas, minicursos e palestras para os profissionais da educação. Além disso, são garantidos, em boa parte das escolas, encontros de coordenadores pedagógicos que oportunizam discussão, reflexão e tomada de decisões acerca de situações pedagógicas de importância e natureza diversas.

Atreladas às poucas oportunidades formativas, os educadores de EJA ainda precisam lidar com dificuldades do cotidiano escolar que versam sobre a falta de espaço físico adequado para realização dos encontros formativos; indisponibilidade de tempo ou de organização de horários para realização de encontros coletivos; escassez de material didático específico para a modalidade de Educação de Jovens e Adultos; carência de recursos financeiros para melhoria dos processos formativos em EJA, dentre outras dificuldades que assolam a vida, o trabalho e a formação continuada do docente da EJA.

A formação continuada dos educadores, embora assegurada por lei, atravessa um momento de pouca efetivação na realidade concreta e nas ações dos municípios que, carentes de incentivos e formação, ofertam a EJA de forma ainda pouco atrelada aos preceitos legais, haja vista ser notória a atenção conferida pela legislação nacional à modalidade.

Essa preocupação com a formação de educadores para atuar na EJA, manifesta na legislação, pode ser claramente percebida na Lei no 9394/96 (BRASIL, 1996), também nas Diretrizes Curriculares Nacionais para a Educação de Jovens e Adultos (DCNEJA), que estabelecem, no item VIII, concernente à Formação Docente, que o preparo do profissional da educação deve 
contemplar, além das exigências formativas para todo e qualquer professor, aquelas relativas à complexidade diferencial dessa modalidade de ensino.

Ao evidenciar as necessidades formativas voltadas para a Educação de Jovens e Adultos, os dispositivos legais deixam evidente a obrigatoriedade da busca pelo preparo que deve ser perseguido pelo educador de EJA.

No caso da Educação de Jovens e Adultos, mesmo que os processos formativos sejam buscados para atender ao mundo do trabalho, podem-se conceber esses processos como atrelados à educação na medida em que se assume a modalidade de EJA como diferenciada, privilegiando aspectos humanos e relacionais, talvez pouco percebidos e/ou reforçados em outras modalidades e/ou níveis de ensino. Mais uma vez, reforça-se a ideia de que o grande diferencial dentro da formação em EJA é o educador na assunção da sua postura e compromisso com o educando. Ser educador de EJA implica disposição para aproximações que passeiam entre os saberes legitimados no campo das ciências e saberes experienciados e legitimados no reencontro com o espaço escolar.

A formação continuada pode ser caracterizada como uma tentativa de resgatar a figura do educador, tão carente do respeito devido a sua profissão. "Ninguém nasce educador ou marcado para ser educador. A gente se faz educador, a gente se forma, como educador, permanentemente, na prática e na reflexão da prática" (FREIRE, 1996, p. 58).

Essa formação dos educadores para atender à EJA tem de partir do campo de prática desses formadores e agregar os conhecimentos necessários, selecionados como valorosos para a modalidade, em seus fundamentos e com as mediações didáticas necessárias, sobretudo, por se tratar de formação docente para trabalhar nas classes de Educação de Jovens e Adultos.

\section{NOVA PERSPECTIVA DE FORMAÇÃO: O PROFESSOR REFLEXIVO E PESQUISADOR}

No contexto da Educação de Jovens e Adultos, em que os educadores precisam reconfigurar sua atuação em face das demandas do universo da modalidade, tomar a prática docente reflexiva como um caminho a ser percorrido desde o início da formação parece uma boa alternativa para assegurar processos formativos sólidos.

Segundo Contreras (2002), a prática dos professores precisa ser analisada, posto que a sociedade seja plural, no sentido da pluralidade dos saberes, mas também desigual, no sentido das desigualdades sociais, econômicas, culturais e políticas. Desigualdades essas já constatadas nas vivências dos educandos de EJA e que os docentes precisam refletir para encontrar caminhos de ação diante desses contextos. A reflexão da prática requer imersão consciente do sujeito no mundo da sua experiência, um mundo carregado de valores, intercâmbios simbólicos, trocas afetivas, interesses sociais e espaços políticos.

É a partir da apropriação dos elementos do contexto, atrelados ao arcabouço, que o professor tem consciência de que a prática vai se consolidando como campo de efetivação de saberes e fazeres da docência. Nesse sentido, Pimenta (2012) afirma que os saberes são construídos no cotidiano do exercício docente e resumemse na experiência e no conhecimento do saber pedagógico consolidado na ação, no qual a prática não só é objeto de reflexão, como também de ressignificação.

É pensando reflexivamente a prática como elemento formativo que diversos autores, como Nóvoa (1992), Perrenoud (2001) e Pimenta (2012), apoiam a ideia de que o educador reflexivo se forma também no interior das suas salas de aula. Desse modo, os conhecimentos produzidos pelos educadores no cotidiano das escolas, além de referendarem suas práticas, podem servir como elemento de reflexão para construção de novas teorias.

Essa é uma possibilidade a ser perseguida pelos educadores da EJA, já que, dadas as especificidades da modalidade, aqueles educadores que realizam um trabalho pautado nos fundamentos da Educação de Jovens e Adultos, certamente, poderão "iluminar" a prática de outros educadores ou mesmo de outros níveis e etapas da educação básica. O que é preciso evidenciar, por meio dessas discussões, é que o educador possui um potencial formador que deve ser socializado no contexto da reflexão da prática. É aí que reside o processo articulado de açãoreflexão-ação.

A aprendizagem da profissão docente se dá por caminhos variados, mediante contribuições das teorias, mas também das experiências acumuladas. É nesse sentido que o aprender a ser educador de EJA, nos processos de formação inicial e continuada, requer constante busca solitária e coletiva pelos melhores métodos, pelas melhores teorias, pelas melhores metodologias que amparem as variadas necessidades do contexto da EJA. Segundo Libâneo (2012, p. 86), "[...] o melhor programa de formação de professores seria aquele que contemplasse melhor, no currículo e na metodologia, os princípios e processos de aprendizagem válidos para os alunos das escolas comuns".

Desse modo, um programa de formação que dê conta da demanda da EJA não pode se vincular unicamente ao discurso teórico, uma vez que a teoria deve estar atrelada à prática em uma relação de mão dupla. Para alcançar essa via de trocas que convirja para a melhoria da prática e, por conseguinte, para a melhoria da qualidade da EJA, é necessária a articulação conjunta entre educadores, educandos, instituições formadoras e a própria instituição de atuação docente. Essa maneira de consolidar a 
formação desencadeia novas discussões voltadas para o desenvolvimento da capacidade de reflexão crítica do educador, tendo como base, além dos conhecimentos teóricos fomentados pelas instituições formadoras, a própria experiência no desenvolvimento da prática.

É nessa perspectiva que se acredita não ser possível desenvolver um trabalho em EJA sem a constante reflexão da prática, uma vez que se fala de um tipo de ensino que deve conduzir a aprendizagens consubstanciadas em um contexto social carregado de demandas. Para Pimenta (2012), ao expor a importância da análise e da reflexão nas práticas e em seus contextos, coloca-se em evidência a escola como espaço institucional de práticas coletivas. Essa concepção traz consigo outra: a da reflexão coletiva.

Trocas compartilhadas entre os docentes, formas plurais de se perseguir a construção da prática: é disso que trata a reflexão coletiva. Para Nóvoa (1992), o professor deve refletir sobre sua ação, pois a produção de práticas educativas eficientes surge da reflexão da experiência pessoal compartilhada entre os colegas.

Desses intercâmbios estabelecidos entre os docentes, muitas concepções, ações e modos de fazer a educação são ressignificados, implementados ou mesmo extintos a depender da interpretação que deles fazem os educadores. $\mathrm{O}$ educador reflexivo indaga-se constantemente sobre o que faz na sala de aula, por que está fazendo e para quem. Dessas reflexões em contexto educativo, emanam reflexões igualmente profundas que marcam também o social. É aí que se desenvolve a concepção do professor como intelectual crítico, ou seja, cuja reflexão é coletiva no sentido de incorporar a análise dos contextos escolares em um contexto maior e dar uma clara dimensão à reflexão: um compromisso emancipatório de transformação das desigualdades sociais (PIMENTA, 2012).

Esse compromisso faz cotidianamente parte do trabalho em EJA, já que dentro da própria sala de aula se encontram os reflexos das desigualdades. Contudo, não se pode negar que entre o discurso e a ação transformadora existe uma densa fronteira. Portanto, muitos educadores, ainda que com anseios emancipatórios, veem-se imersos em um paradoxo de pressões e tensões, desencadeadas, muitas vezes, pelo próprio contexto social e institucional. Para Pimenta (2012, p.33), “[...] a compreensão dos fatores sociais e institucionais que condicionam a prática educativa e a emancipação das formas de dominação que afetam o pensamento e a ação não são espontâneas e nem se produzem naturalmente". Percebe-se, pois, tratar-se de processos perenes de descoberta, de transformação das diferenças das práticas docentes cotidianas.

De todo modo, embora as tentativas de mudanças não se efetivem em curto prazo, essas atitudes são importantes na medida em que revelam que o educador tem se tornado capaz de refletir sobre sua prática, de buscar novas estratégias, de não se conformar com o que está posto. É por meio da reflexão que se produz a prática educativa.

Perrenoud (2002) faz alguns apontamentos voltados à construção da prática refletida, no sentido de se considerar a experiência como parte da reflexão do que se fez. Para esse autor, se o educador não dispõe de tempo para refletir no ato da ação, ele pode, em contrapartida, relembrar e revisar os acontecimentos do dia, fazendo um trabalho de compreensão e de reinterpretação.

Para uma formação reflexiva, é preciso que o educador perceba que o exame de sua prática se constitui em um dos elementos mais importantes de melhoria. Um professor reflexivo tem mais possibilidades de atingir êxito em sua atuação, já que, buscando aprender mais, pode efetuar mudanças eficazes em sua prática (PERRENOUD, 2002).

O educador reflexivo é o investigador de sua ação, é o pesquisador de sua própria prática e também da de seus parceiros. É o cientista da educação que não somente assimila conhecimentos, mas produz outros capazes de serem disseminados. Segundo Pimenta (2012, p.51), "[...] o professor pode produzir conhecimento a partir da prática, desde que na investigação reflita intencionalmente sobre ela, problematizando os resultados obtidos com o suporte da teoria. E, portanto, como pesquisador de sua própria prática".

Para que os anseios de um educador investigador de sua ação sejam reveladores, é necessário pensar em uma formação que promova reflexões das problemáticas vivenciadas e das atividades realizadas no contexto da EJA. É preciso arquitetar e desenvolver uma política de formação que valorize os educadores e as instituições como capazes de pensar (PIMENTA, 2012), como capazes de organizar os saberes científicos, pedagógicos e da experiência na proposição das necessárias modificações das práticas com fins à garantia do direito de ensinar e de aprender em EJA. A organização dos processos formativos deve estar compromissada com um ensino que logre resultados de qualidade para todos os jovens e adultos.

Para que as perspectivas em direção a uma educação de jovens e adultos de qualidade sejam alcançadas, são necessárias, além de um profundo investimento na formação inicial e continuada dos educadores, condições de trabalho e valorização dos profissionais da educação. É preciso que se estabeleçam políticas que modifiquem as jornadas de modo a se tornarem integrais. É necessário um aumento de salário que confira dignidade ao educador, bem como fomente parcerias entre instituições superiores sérias e comprometidas com a formação docente. Isso porque é por meio das instituições superiores que os educadores de EJA se apropriarão da formação sólida que, agregada à formação experiencial, promoverá um trabalho que eleve a qualidade da EJA. 


\section{NECESSIDADES FORMATIVAS DOS EDUCADORES: DO REVELADO À INTERPRETAÇÃO E DISCUSSÃO DOS RESULTADOS}

A formação do educador da Educação de Jovens e Adultos requer, no âmbito da implementação das políticas públicas, mais seriedade no que versa sobre as especificidades educativas inerentes aos educandos.

Como se tem discutido até então, a precarização histórica em torno da EJA e de suas especificidades acarretou dificuldades no âmbito das políticas públicas, das práticas pedagógicas, da profissão docente, assim como no âmbito da formação inicial e continuada.

Segundo Soares (2006), a pouca atenção às especificidades da EJA nos processos de formação conduz à desqualificação profissional, levando professores do ensino regular a atuarem na EJA, o que compromete o trabalho e despotencializa os educandos em suas possibilidades de aprendizagem. A realidade estadual não difere da realidade nacional, pois os educadores participantes do estudo são também educadores do ensino regular e carecem de processos formativos voltados à modalidade.

Originários de variadas áreas de formação inicial, consideradas pelos próprios educadores como sendo vagas e pouco representativas da modalidade, e preparados, na maioria dos casos, para lecionar no ensino regular, os educadores iniciam o trabalho na EJA por diferentes interesses e motivações: conveniência do horário noturno, melhoria do salário, possibilidade de conciliar mais de uma atividade profissional, dentre outros.

$\mathrm{Se}$ as razões pessoais assinalam o começo da experiência docente na EJA, a opção por continuar, geralmente, deve-se à percepção da relevância da escolarização destinada aos educandos e à capacidade de sensibilização que suscitam as histórias de vida, construídas no histórico de exclusão que passam essas populações jovens e adultas. A partir do momento em que os educadores se percebem dentro do universo da EJA, as inclinações pessoais começam a requerer as motivações político-pedagógicas e epistemológicas inerentes ao trabalho com jovens e adultos. É daí que surgem as necessidades do educador em perseguir uma formação que dê conta de assessorá-lo em seus processos educativos em EJA.

É certo que, no desenvolvimento da prática, todo educador aprende com seu trabalho, mas também é certo que o processo espontâneo, por si só, não dá conta de preparar o educador para o enfrentamento de uma realidade, que exige o aperfeiçoamento das práticas e, por isso, a formação permanente. Como afirma Di Pierro (2006, p. 287),
A formação de educadores em serviço não pode ser esporádica ou descontínua; precisa ser permanente e sistemática, já que requer tempo de amadurecimento e de sedimentação que venha a incidir não apenas sobre os conhecimentos e as competências, mas também sobre os valores e as atitudes do educador.

No universo de atuação dos educadores, as percepções foram claras no que diz respeito à escassez ou à inexistência de processos formativos voltados à EJA. Ao serem indagadas acerca da participação em cursos de formação continuada, as respostas, em quase sua totalidade, atestaram a escassez da formação permanente.

\begin{abstract}
"No momento, não estou participando de nenhum curso, mas já participei de alguns que, mesmo não sendo específicos da EJA, me ajudaram a entender o universo dos adultos. Participei, por exemplo, do Progestão e, mesmo não sendo um curso específico, me ajudou a entender melhor a educação. Tudo que puder somar já é válido. Mas formação diretamente relacionada à EJA, infelizmente, a gente não participa, até porque não temos essas ofertas." (Educadora E)

"Participo das Jornadas Pedagógicas uma vez por ano, mas as jornadas têm sido cada vez mais direcionadas ao ensino regular; é raro ter alguma coisa específica da Educação de Jovens e Adultos. Então, a gente sente a necessidade de participar de formações que nos ajudem na prática, mas essas formações não têm acontecido.” (Educadora G)

"As oportunidades de formação continuada são poucas, mas nós, professores da Educação de Jovens e Adultos, também não tivemos oportunidade de aprofundar o entendimento e a compreensão da EJA na nossa graduação. Então, o desenvolvimento do trabalho vai ficando complicado porque, se a formação inicial foi deficiente, a formação continuada vai seguindo também na dificuldade." (Educador F)
\end{abstract}

É de consenso de todos que a formação continuada é essencial. Entretanto, como afirma Moura (2006), esta se ressente de uma base teórica sólida por parte dos educadores, que deveria ser proporcionada por meio de uma consistente formação inicial, essencialmente por considerar as peculiaridades dos jovens e adultos sujeitos da prática pedagógica.

A carência da formação inicial, consequentemente, implica vazios de saberes científicos e pedagógicos na trajetória profissional que se constituem em necessidades que são conduzidas para os processos de formação continuada. Ocorre que, como revela Nóvoa (1991, p. 24), "[...] parece evidente que, tanto as universidades como as escolas, são incapazes isoladamente de responder a estas necessidades".

A percepção das limitações das instituições formativas, nomeadamente no que se refere ao universo 
da EJA, aponta para a necessidade de uma articulação entre instituições formativas externas e instituições mais próximas à realidade baiana. $\mathrm{O}$ caminho de formação continuada se processa como uma necessidade endógena dos docentes em romper com os vazios da formação inicial, esta emanada do exercício da prática em EJA.

As exigências de formação continuada apontadas pelos educadores de EJA repousaram bem mais no bojo da trama local que fora disso. Tal como apontam os relatos que se seguem, os educadores dão indícios de que desejam uma formação continuada sistematizada, realizada no interior das escolas, de modo a criar ambiente propício e eficaz para o atendimento às suas necessidades no cotidiano da instituição.

"Não acontecem, por parte da instituição de atuação, formações que nos auxiliem no trabalho com a Educação de Jovens e Adultos. Há apenas algumas oficinas durante a jornada pedagógica, no início do ano letivo, mas geralmente não são específicas, não atendem às nossas necessidades formativas." (Educadora D)

"Não temos formação em EJA, sentimos essa falta. Hoje são muitas universidades e muitas propostas de cursos, mas precisamos também de formação dentro da escola. Como ouvi numa palestra outro dia, precisamos criar nossos espaços de formação e esses espaços precisam ter nossa cara, precisam partir de nossa realidade. Nada melhor do que fazer essas formações aqui, no nosso chão.” (Educadora $\mathrm{H}$ )

$\mathrm{O}$ anseio expresso pelos educadores de que a escola se torne um espaço de formação voltada à EJA encontra ressonância no que propõe Alarcão (2003), ao ressaltar que, para que os professores se tornem autênticos profissionais do desenvolvimento humano, é necessário que a escola seja, antes de tudo, um centro de formação para todos os que nela convivem e que esteja organizada para vivenciar, em conjunto, seu projeto de formação.

Diante das lacunas teóricas que ainda hoje acompanham a formação e, consequentemente, o trabalho dos educadores de jovens e dos adultos, mais do que desqualificar as práticas desenvolvidas, é preciso convidá-los a refletir sobre a qualidade do trabalho na EJA e encontrar novos caminhos de formação. Nesse empenho, faz-se necessário escutar o que cada educando deseja para sua formação escolar, para que, atrelados aos seus apelos, os educadores possam buscar aportes formativos para a construção do fazer docente. Foi no intuito de contribuir para a busca dos aportes formativos em EJA que foram levantadas as necessidades formativas dos educadores, tal como exposto no gráfico mais à frente.

Os dados revelaram que a maior necessidade dos educadores de EJA está na formação continuada (33\%), seguida das necessidades relacionadas à prática (24\%), aparecendo depois as necessidades voltadas à própria condição de serem educadores de EJA (19\%). Na sequência, evidenciam-se as necessidades curriculares com foco na EJA (14\%) e, por fim, as necessidades correlatas ao apoio da gestão nas instituições de EJA $(10 \%)$.

De todas as necessidades apontadas pelos educadores, a formação continuada encontra um lugar de destaque, assim como a prática. Isso reforça a relação entre prática e formação docente.

Se a prática e a formação continuada são entendidas como indispensáveis à promoção do desenvolvimento do educando jovem e adulto, os educadores não podem prosseguir com carências, nem no âmbito da prática, nem no âmbito da formação. Desse modo, os dados apresentados graficamente sobre as necessidades formativas dos educadores de EJA precisam dar lugar a perspectivas de mudanças.

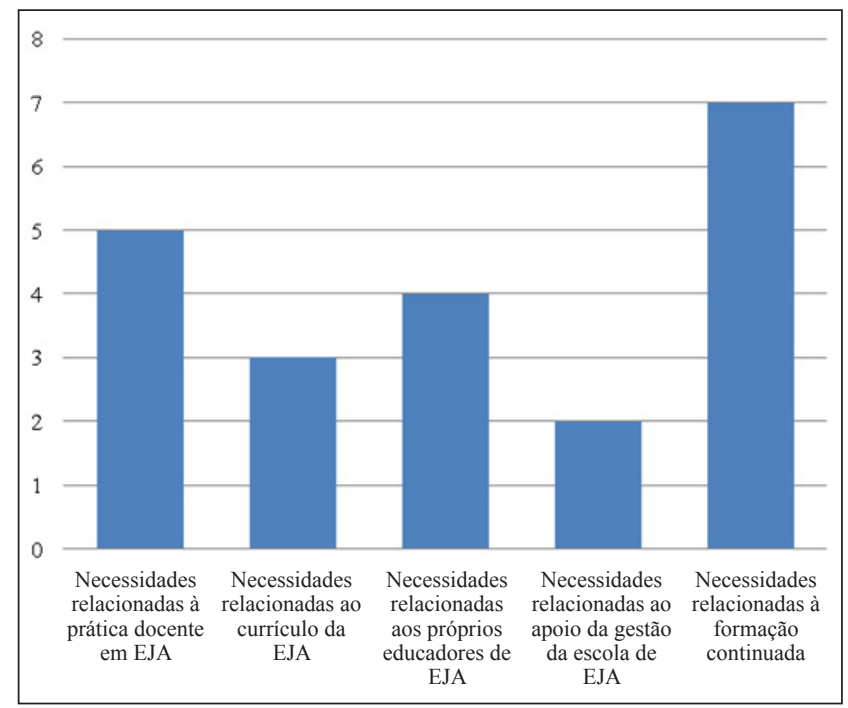

Figura 1. Necessidades formativas dos educadores de EJA (Fonte: Dados emanados das entrevistas realizadas com os informantes - 2014)

Como se constata na revelação dos próprios educadores, é urgente a necessidade de formação continuada para os docentes da EJA. Uma formação que evidencie a articulação teórico/prática, que acolha as especificidades da educação de jovens e adultos, que aconteça de forma perene, quer seja através da oferta assegurada pelas secretarias dos estados e municípios, quer seja pelas universidades.

Os educadores que atuam na EJA disseram sentir dificuldades para a realização do trabalho pedagógico em função da escassez de materiais, de apoio técnicopedagógico incipiente, de falta de condições próprias ao 
trabalho com jovens e adultos, o que se configura pela carência de formação continuada desses educadores para dar conta das especificidades da atuação docente na Educação de Jovens e Adultos.

As condições necessárias à realização do trabalho pedagógico na EJA envolvem tanto o aprofundamento teórico e conceitual da modalidade e das áreas que cada docente atua quanto o compromisso com um trabalho docente diferenciado. Isso envolve a adoção de metodologias e posturas que deem conta de vencer as dificuldades de permanência, aprendizagem e relacionamentos, que abarquem uma condição educativa de direitos conquistados e que sejam capazes de reconfigurar a realidade da EJA na escola pública.

\section{CONSIDERAÇõES FINAIS}

As considerações finais do estudo revelam o sentimento de que ainda há muito que perseguir no âmbito da formação de educadores de EJA, na Bahia e no Brasil. Com isso, ressalta-se, desde então, que as conclusões não são fechadas em si mesmas, mas abertas a novas possibilidades de produção de conhecimentos mediante itinerários percorridos e realidades vivenciadas.

Ao focalizar a formação inicial e continuada dos educadores, busca-se delinear suas necessidades no campo de atuação. Como resultado disso, foi notado que as fragilidades passeiam entre o campo das práticas docentes, do currículo, do pouco apoio da gestão escolar, da pouca valorização profissional do educador e, sobretudo, das limitadas condições de formação continuada.

As necessidades formativas identificadas pelos educadores vieram à tona como respostas à problemática desta investigação e como consecução dos objetivos perseguidos. No entanto, mais do que encontrar os problemas que acometem a EJA, é preciso que sejam apontadas algumas saídas para a problemática vivenciada. Desse modo, este estudo aponta, entre tantas coisas, para a urgente importância do estabelecimento de ações com foco na formação docente, o que, consequentemente, poderá desencadear atuações mais condizentes com os preceitos da modalidade e dos educandos nela inseridos.

A carência de momentos específicos de formação implica não somente a desqualificação da atuação docente, como também desmotiva os educadores da modalidade, tornando-os ainda mais fragilizados diante da pouca valorização demonstrada a eles e à modalidade.

Dentro dessas condições, pontuam-se, além da infraestrutura física e material, currículos adequados à modalidade da EJA, condições de atendimento das especificidades dos educandos, valorização dos profissionais da EJA. E aqui se incluem salários justos e perene formação dos educadores por meio da obrigatoriedade da existência de disciplinas sobre a EJA nos currículos das licenciaturas, da promoção de especializações e da formação continuada no âmbito da modalidade.

Antes que essas formações específicas aconteçam, a EJA continuará a ser conduzida de modo improvisado pela ação dos próprios docentes que, diante de todas as limitações, ainda buscam individualmente ou de forma coletiva os subsídios possíveis para a formação e para o desenvolvimento das práticas. Como afirma Charlot (2012), é preciso respeitar o trabalho dos educadores, pois eles se fazem educadores de EJA e, por suas próprias experiências e práticas, constroem a profissão docente em EJA.

O necessário respeito em relação ao profissional que atua na EJA e às suas formas de escape para conseguir dar conta do trabalho na modalidade, no entanto, não pode tornar os olhares míopes diante da necessidade de visualizar saídas para assegurar o processo de formação desses educadores. A dedicação, a busca cuidadosa, o compromisso do educador de EJA para com seu trabalho são elementos importantíssimos para a consecução da prática, mas não são suficientes para uma construção séria da EJA. É preciso uma procura mais minuciosa por programas definidos de formação de educadores.

A escassez de estudos e formações voltadas à EJA fragiliza as práticas dos educadores da modalidade, pois os momentos coletivos de formação são de suma relevância para a ação dos educadores, além de permitir o constante exercício da reflexão sobre a prática.

No sentido dessa articulação entre teoria e prática, no contexto da EJA, foi aventado, por parte de alguns dos educadores, o desejo de participarem de grupos de estudos que acoplassem momentos de estudos teóricos com momentos de vivências voltadas às atividades práticas. Alguns educadores evidenciaram a importância do desenvolvimento de trabalhos compartilhados e com o envolvimento dos alunos e da comunidade escolar. De certa forma, esses desejos apontam a necessidade de que as instituições formadoras valorizem a escola como espaço de formação pelo intercâmbio que pode oportunizar, pelos encontros entre educadores que contribuem para a melhoria da prática e pelos estudos em grupos menores. $\mathrm{O}$ que reduz o isolamento do processo de aprendizagem. Enfim, pela grandeza das vivências que essas situações proporcionam, por serem, também, espaços formativos.

É, nesse sentido que se apontam, nessas recomendações, algumas indicações tiradas de todo esse processo de leitura e de busca empírica nos espaços da EJA. Como primeira recomendação, acredita-se que os cursos de Pedagogia e demais licenciaturas devem inserir em seus currículos as questões que envolvem a modalidade de EJA, já que os estudantes de graduação, 
ao se tornarem profissionais da educação, poderão ser encaminhados para o trabalho na EJA. Uma vez atuando na modalidade, esses profissionais precisarão de uma formação específica que lhes permita atuar.

Ao estabelecer uma discussão acerca da maneira como a formação de professores para atuar na EJA é tratada nos cursos de licenciaturas, percebe-se que, por um lado, ainda que as Diretrizes Curriculares Nacionais DCNs dos cursos específicos não mencionem diretamente a EJA, todas destacam que se devem considerá-las para a formação de professores em nível superior. Desse modo, já que esse documento revela a necessidade de um olhar e de uma atuação diferenciada que reconheça a modalidade, então cada licenciatura possui a condição de dar ênfase à EJA, caso seus currículos se abram à modalidade. Mas, se de um lado é possível que as licenciaturas contemplem a EJA, de outro lado, as diretrizes das áreas de conhecimento específico apresentam uma feição enciclopédica e não trazem uma discussão mais aprofundada de seu escopo na educação básica, uma vez que a atividade docente ocupa um lugar secundário nos cursos (GATTI; BARRETO, 2009). Isso faz com que as diretrizes para formação de professores acabem sendo o único documento que aponta parâmetros para a atuação nos distintos níveis e modalidades da educação básica. Nesse sentido, adverte que poucos são os cursos que propõem disciplinas específicas sobre a EJA no campo das licenciaturas.

Pensando na particularidade da EJA, de acordo com Ventura (2012), nem mesmo os cursos de Pedagogia dão ênfase à modalidade em suas especificidades, já que, além das mudanças nas matrizes curriculares que acabam comprometendo a regularidade da oferta, pode ocorrer, nas licenciaturas, certo descaso no que diz respeito aos fundamentos e relevância da modalidade. É nesse sentido que Machado (2008) afirma que a primeira questão a ser enfrentada pela formação de professores da EJA é repensar os currículos dos cursos de licenciatura, para que a formação inicial trate da modalidade de ensino.

Em um recente estudo em que toma como base outras pesquisas já realizadas, Soares (2006) revela que são extremamente raros os cursos de Pedagogia que oferecem habilitação em EJA e que há certa expansão na região sul. $\mathrm{O}$ autor ainda ressalva que, contraditoriamente, a proposta das novas diretrizes curriculares para o curso de Pedagogia parece impulsionar as reformulações curriculares que extinguem a habilitação em outras regiões. Pelas pesquisas já realizadas, constata-se que as fragilidades dos cursos de formação de professores são ainda maiores quando se fala da EJA.

Ainda no âmbito desses apontamentos, como uma segunda recomendação, acredita-se que as universidades e demais instituições de ensino superior precisam incen- tivar e valorizar o desenvolvimento de estágios e projetos voltados à EJA, já que iniciativas dessa ordem podem envolver os graduandos com o campo da EJA na medida em que lhes oportuniza atrelar a teoria com a prática.

Uma terceira recomendação diz respeito à necessidade de as instituições de ensino superior adotarem em seus currículos intercâmbio de experiências entre os educadores para a reflexão sobre a prática. Disso advém a importância dos encontros entre os educadores como possibilidades de formação direcionada à prática.

Para contemplar tudo que foi revelado por este estudo, pode-se afirmar que os educadores de EJA, de modo geral, necessitam de formação em EJA e, para isso, precisam de políticas públicas de formação de educadores. É urgente que processos consistentes sejam pensados a fim de buscar possibilidades para que os educadores tenham a formação continuada no interior e fora dos seus espaços de trabalho, em uma constante integração da teoria com a prática, ambas complementares e fundamentais ao educador de EJA na construção do seu processo formativo.

\section{REFERÊNCIAS}

ALARCÃO, Isabel. Formação continuada como instrumento de profissionalização docente. In: VEIGA, Ilma Passos A. (Org.). Caminhos da profissionalização do magistério. 3. ed. Campinas: Papirus 2003. p. 99-136. (Coleção Magistério: Formação e Trabalho Pedagógico).

ALVES-MAZZOTTI, Alda Judith; GEWANDSZNAJDER, Fernando. $\mathbf{O}$ método nas ciências naturais e sociais: pesquisa quantitativa e qualitativa. São Paulo: Thomson, 2002.

BARDIN, Laurence. Análise de conteúdo. Lisboa: Edições 70, 1988.

BOGDAN, Robert; BIKLEN, Knopp Sari. Investigação qualitativa em educação: uma introdução à teoria e aos métodos. Portugal: Porto, 1994.

BRASIL. Constituição: República Federativa do Brasil. Brasília: Senado Federal, 1988.

. Lei no 9.394, de 20 de dezembro de 1996. Estabelece as diretrizes e bases da educação nacional. Brasília, 20 dez. 1996.

Ministério da Educação. Conselho Nacional de Educação. Parecer CNE/CEB no 11/2000. Diretrizes Curriculares Nacionais para a Educação de Jovens e Adultos. Brasília: maio de 2000. Disponível em: <http://www.mec.gov. br/cne/pdf/PCB11_2000.pdf >. Acesso em: 08 ago. 2015.

Instituto Brasileiro de Geografia e Estatística - IBGE. Censo Demográfico 2010. Disponível em: <www.ibge.gov.br>. Acesso em: 22 abr. 2014.

CONTRERAS, Domingo José. Autonomia de professores. São Paulo: Cortez, 2002.

DI PIERRO, Maria Clara. Contribuições do I Seminário Nacional de Formação de Educadores de Jovens e Adultos. In: SOARES, Leôncio (Org.). Formação de Educadores de Jovens e Adultos. Belo Horizonte: Autêntica/Secad-MEC/ Unesco, 2006. 
Seis anos de Jovens e Adultos no Brasil: os compromissos e a realidade, São Paulo: Ação Educativa, 2003.

FREIRE, Paulo. Pedagogia da autonomia: saberes necessários à prática educativa. São Paulo: Paz e Terra, 1996.

GATTI, Bernadete Angelina; BARRETO, Elba Siqueira de Sá. Professores do Brasil: impasses e desafios. Brasília: Unesco, 2009.

GONZALEZ REY, Fernando. Pesquisa qualitativa e subjetividade: os processos de construção da informação. São Paulo: Pioneira Thomson Learning, 2005.

LIBÂNEO. José Carlos. Reflexividade e formação de professores: outra oscilação do pensamento pedagógico brasileiro? In: PIMENTA, Selma Garrido; GHEDIN, Evandro (Orgs.). Professor reflexivo no Brasil: gênese e crítica de um conceito. 7. ed. São Paulo: Cortez, 2012.

MACHADO, M. M. A prática e a formação de professores na EJA: uma análise de dissertações e teses produzidas no período de 1986 a 1998. In: REUNIÃO ANUAL DA ANPED, 23., Associação Nacional de Pós-Graduação e Pesquisa em Educação, Caxambu, 2000.

Formação de professores para a EJA: uma perspectiva de mudança. Retratos da Escola, Brasília, v. 2, n. 2-3, p. 161174, jan./dez. 2008.

MARCONI, Marina de Andrade; LAKATOS, Eva Maria. Técnicas de pesquisa. In: MARCONI, Marina de Andrade; LAKATOS, Eva Maria. Fundamentos de metodologia científica. 6. ed. São Paulo: Atlas, 2009.

MOURA, Tânia Maria de Melo. Os estudos e as pesquisas sobre a formação de professores para a educação de jovens e adultos: Uma releitura do silêncio, dos vazios e das lacunas institucionais no Estado de Alagoas In: SOARES, Leôncio
(Org.). Formação de Educadores de Jovens e Adultos. Belo Horizonte: Autêntica/Secad-MEC/Unesco, 2006.

NÓVOA, A. (Org.). Vida de professores. Porto, Portugal: Porto Editora, 1992.

Profissão professor. Porto: Porto Editora, 1991.

PERRENOUD, Philippe; ALTET, Marguerite; CHARLIER, Évelyne. Formando professores profissionais: quais estratégias? Quais competências? Tradução de Fátima Murad e Eunice Gruman. 2. ed., rev. Porto Alegre: Artmed, 2001.

A prática reflexiva no ofício de professor: profissionalização e razão pedagógica. Porto Alegre: Artmed, 2002.

PIMENTA, Selma Garrido; GHEDIN, Evandro (Org.). Professor reflexivo no Brasil: gênese e crítica de um conceito. 7. ed. São Paulo: Cortez, 2012.

PLANO MUNICIPAL DE EDUCAÇÃO - Município de Matina (BA). Bahia, 2015-2025, Lei no 32, de 16 de junho de 2015.

SOARES, Leôncio. Aprendendo com as diferenças: estudos e pesquisas em Educação de Jovens e Adultos, 2. ed. Belo Horizonte: Autêntica, 2006.

Educação de Jovens e Adultos. Rio de Janeiro: $\overline{\mathrm{DP} \& A}, 2002$.

VENTURA, Jaqueline. A EJA e a formação docente nas licenciaturas. Revista da Faeeba, v. 21, n. 37, p. 71-82, jan./ jun. 2012.

YIN, R. Estudo de caso: planejamento e métodos, 2. ed. Porto Alegre: Bookman, 2001.

Recebido em 19-11-2015.

Aprovado em 30-04-2017. 